\title{
Early Diagnosing of Urinary Tract Anomalies
}

\author{
Islam Mamica $^{1 *} \quad$ Gerta Halilaj $^{2} \quad$ Rustem Celami $^{3} \quad$ Aqif Gjokutaj $^{4} \quad$ Krenar Preza $^{4} \quad$ Utku Akgor $^{5}$ \\ 1.Radiologist, Radiology Service, City Hospital, Mat, Albania \\ 2.Imagery Technician, Shefqet Ndroqi University Hospital and Lecturer at Aldent University, Tirana, Albania \\ 3.Obstetrician and Gynecologist, American Hospital Albania; Professor, Aldent University, Tirana, Albania \\ 4.Radiologist, Professor, University of Medicine, Tirana, Albania \\ 5.Obstetrician and Gynecologist, Hacettepe University Hospitals, Ankara, Turkey
}

\begin{abstract}
Nowadays, with advanced diagnostic technology and accessibility of patients to qualified physician, many anatomical anomalies are diagnosed in uterine life, including urinary tract anomalies in prenatal period, however, even with advanced of technology, many of such anomalies continue to be diagnosed later on, in early stage of life or even later when a medical problem arise as a consequence of these anomalies. In Albania, nowadays, high technology and high definition diagnostic imaging machines are available; however, we do face lack of qualified and experienced medical specialist, especially in peripheral regions - city hospitals throughout Albania. Early diagnosing of anomalies like urinary tract ones, are possible to be diagnosed since the end of first trimester of pregnancy by 14 weeks, and later on during the anatomic ultrasound examination or otherwise called morphologic fetal ultrasound at $18-22$ weeks of pregnancy, if examination carried out by a qualified medical specialist, should clearly visualize fetal urinary tract. However, this fetal problems undiagnosed during pregnancy, there are often diagnosed in postnatal period. In some countries, many ultrasound examinations during pregnancy are performed by ultrasound technicians and interpreted by radiologist or perinatologist, however, generally these examination are performed by fetal medicine specialist, or obstetrician and gynecologists. In Albania these examination are performed only by obstetrician and gynecologist, since qe do not have a fetal medicine center. Any urinary problem during early age, it is appropriate to perform a general abdominal ultrasound examination as fast, reliable and cost-effective examination tool with no side effect.
\end{abstract}

Keywords: Diagnostic, early, urinary, anomalies, medical specialist

DOI: $10.7176 /$ ALST/87-02

Publication date: April $30^{\text {th }} 2021$

\section{Introduction}

Congenital anomalies of urinary tract system are among most common ones. ${ }^{1}$ Urogenital tract system normally represents two main components: urinary and genital system. Until 15-16 weeks of pregnancy rhythm of urogenital development is very rapid and later on decreases. ${ }^{1,2}$

With meticulous examination 1 in 100 - 500 neonate may have an anomaly of urinary system, respectively congenital anomalies of kidney and urinary tract. ${ }^{3}$ Various congenital anomalies do not have signs and symptoms and represent only numerical diagnostic anomalies, some of them may be incapability with life like bilateral renal agenesis. Other urinary tract anomalies may be responsible for obstructive urinary tract pathologies like posterior valve of urethra, stenosis of pelvic-urinary segment, strictures of ureters, ureterocele. Later on, some urinary tract anomalies may be responsible for chronic urinary infections, vesicouretral reflux. In addition, we have some urinary tract anomalies that are base of development of tumors, like urinary vesicle extrophy. Congenital anomalies of kidney and urinary tract may be part of multi-organ processes in single-gene disorders, with dominant or recessive inheritance, as we can find in Fraser syndrome, the branchiootorenal syndrome, Kallmann syndrome, Ehlers-Danlos syndrome and others. ${ }^{4}$

\section{Discussion}

Causes of congenital anomalies of kidney and urinary tract are complex. It is likely thatmixture of genetic and environmental factors contribute todevelopment of kidney and urinary tract abnormalities.Genetic factors involved in most cases of congenital anomalies of kidney and urinary tract are unidentified. Syndrome ofcongenital anomalies of kidney and urinary tract it is thought to be caused by changes in genes associated withspecific syndrome. Variations in these same genes can also underlie some cases of isolated congenital anomalies of kidney and urinary tract.

The fetal kidneys can be visualized from 10 weeks of gestation and are seen in almost all fetuses at 14 weeks using transabdominal ultrasound (ultrasound illustration figure 1). ${ }^{5}{ }^{6}$ They initially appear in the transverse plane as hypoechogenic oval structures on both sides of the fetal spine. In the longitudinal axis, they appear along the paravertebral plane of the fetal spine. A detailed view of the fetal kidneys by transvaginalsonography has enabled development of normograms for the kidney diameters at the first trimester. ${ }^{5}$ 


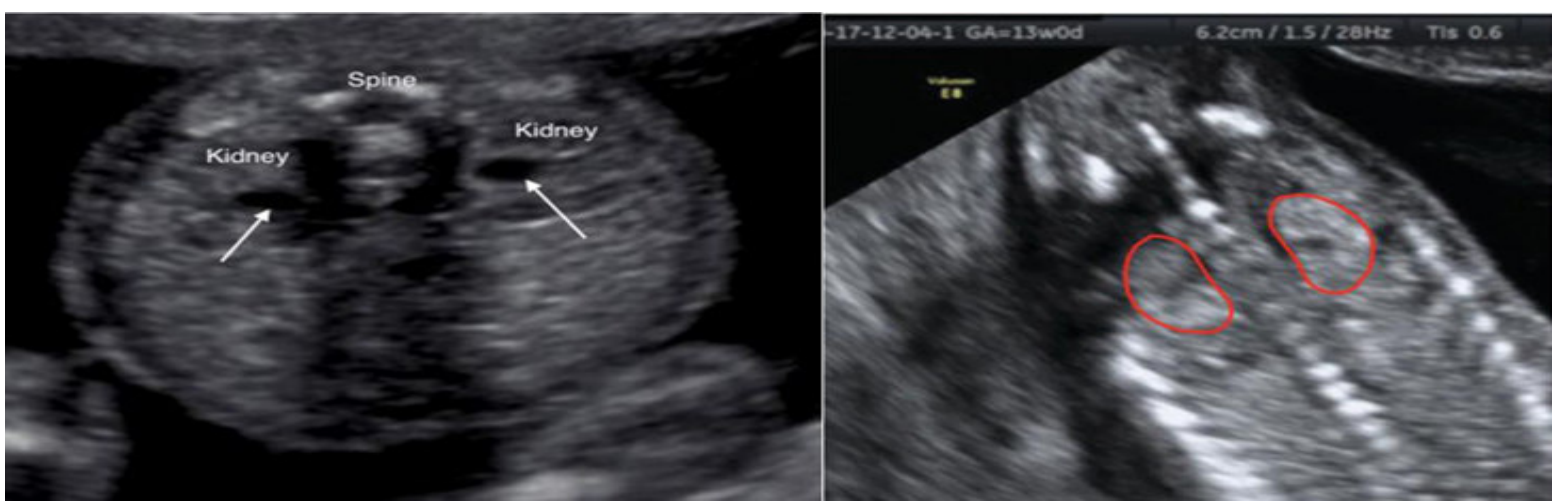

Figure 1.Illustration. Fetal ultrasound, both fetal kidneys visualized.

Bilateral renal agenesis is usually diagnosed at the beginning of second trimester due to anhydramnios. Since most of the amniotic fluid before 11 weeks is not produced by the fetal kidneys, this absence of amniotic fluid cannot help to detect renal agenesis during the first trimester. However, prenatal diagnosis of bilateral renal agenesis has been reported after 12 weeks gestation. ${ }^{6,7,8}$

Internationally, congenital anomalies of kidney and urinary tract are responsible for $40 \%$ to $50 \%$ of pediatric and $7 \%$ of adult end - stage renal disease. ${ }^{9}$ Pathogenic variations in genes causing congenital anomalies of kidney and urinary tract include monogenic diseases such as polycystic kidney disease (illustration figure 2) and ciliopathies, as well as syndromes that include isolated kidney disease in conjunction with other abnormalities.

Antenatal diagnosis most often follows using ultrasonography; however, further genetic diagnosis may be made employing a range of testing approaches. Family history and pathologic examination also provide information to improve ability to make a prenatal diagnosis of congenital anomalies of kidney and urinary tract.

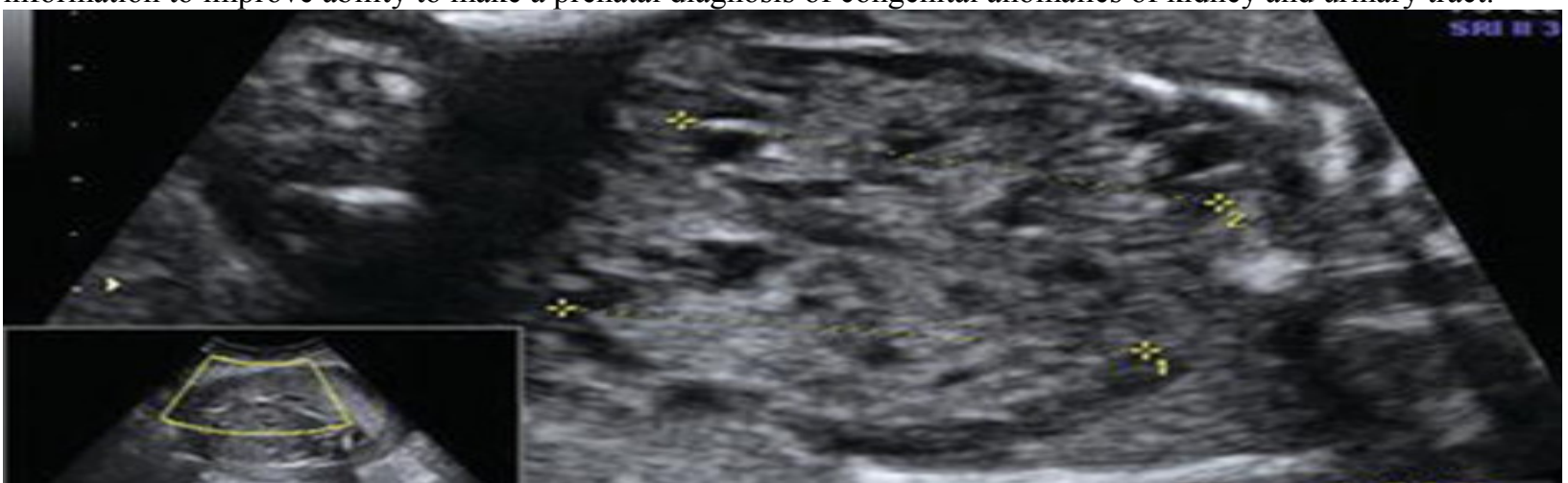

Figure 2. Fetal polycystic kidney disease

In Albania, the high tech diagnostic technology in imagery, respectively ultrasonography and qualified physician are existent, however, mostly they medical practice is concentrated in capital cities, and we have present many cities without such technology and with no any qualified physician. Therefore, making almost $2 / 3$ of Albanian population vulnerable of accessing quality health care service like; fetal medicine, gynecology, obstetrics, and neonatology and other medical specialties as well. So, radiologist may play an important role in fetal medicine, like they do in many other medical systems in western developed countries.

\section{In conclusion}

Diagnostic imaging is playing an important role nowadays, especially with advanced technology incorporated in such service, together with high resolution imaging and of course trained and qualified physician, makes early diagnosing, such a urinary tract anomalies possible in very early stage like intrauterine life. Albanian state authorities in charge of medial political strategies and management should emphasize the role of radiologist in order to employ their clinical skills in bigger accessibility to health care service for a better health care in general.

\section{References}

1. Kurjak A, Chervenak FA, Vladareanu R. Donald School. Textbook of ultrasound in obstetrics and gynecology. Bucharest: Amaltea; 2012. ISBN 978-973-162-104-3. Pages 337-348

2. CALLEN. Ultrasonography in Obstetrics and Gynecology. 6th ed. DrRaduVladareanu-Coordinator of the Romanian edition. Hypocrate; 2017. Pages 508-538

3. LS Chitty, L Hui, A Ghidini, B Levy, J Deprest, T Van Mieghem, DW Bianchi, In case you missed it: The 
Prenatal Diagnosis editors bring you the most significant advances of 2019, Prenatal Diagnosis, 10.1002/pd.5632, 40, 3, (287-293), (2020).

4. Janchevska A, Gucev Z, Tasevska-Rmus L, Tasic V. Congenital Anomalies of the Kidney and Urinary Tract in Children Born Small for Gestational Age. Pril (MakedonAkadNaukUmet Odd Med Nauki). 2017;38(1):53-57. doi:10.1515/prilozi-2017-0007

5. Peter Twining. First-trimester detection of fetal anomalies, Textbook of Fetal Abnormalities, 10.1016/B9780-443-07416-5.50009-5, (41-74), (2007).

6. Celami R. Obstetrical Ultrasound Examination and Biochemical Markers as Contemporary Tool Assessment for Fetal Anomalies in Albania. ALST. Vol.16, 2014; 45-48.

7. Bronshtein M, Yoffe N, Brandes JM, et al: First and early second trimester diagnosis of fetal urinary tract anomalies using transvaginalsonography. PrenatDiagn 10:653, 1990.

8. Sherer OM, McAndrew JA, Liberto L, et al: Recurring bilateral renal agenesis diagnosed by ultrasound with the aid of amnioinfusion at 18 weeks' gestation. Am J Perinato19:49, 1992.

9. Talati AN, Webster CM, Vora NL. Prenatal genetic considerations of congenital anomalies of the kidney and urinary tract (CAKUT). PrenatDiagn. 2019;39(9):679-692. doi:10.1002/pd.5536. 